\title{
Structural study of ball-milled sodium alanate under high pressure
}

\author{
R. Selva Vennila ${ }^{\mathrm{a}, *}$, Vadym Drozd ${ }^{\mathrm{a}}$, Lyci George ${ }^{\mathrm{a}}$, Surendra K. Saxena ${ }^{\mathrm{a}}$, Hanns-Peter Liermann ${ }^{\mathrm{b}}$, \\ H.Z. Liu ${ }^{c}$, Ashley C. Stowe ${ }^{d}$, Polly Berseth ${ }^{d}$, Donald Anton ${ }^{d}$, Ragaiy Zidan ${ }^{d}$ \\ a Center for Study of Matter at Extreme Conditions, Florida International University, Miami, FL 33199, USA \\ ${ }^{\mathrm{b}}$ High Pressure Collaboration Access Team (HPCAT) and Geophysical Laboratory, Advanced Photon Source, Argonne National Laboratory, Argonne, IL 60439, USA \\ ${ }^{\mathrm{c}}$ HPCAT, Geophysical Laboratory, Carnegie Institution of Washington, Building 434E, 9700 South Cass Avenue, Argonne, Illinois 60439, USA \\ d Savannah River National Laboratory, Energy Security Department, Aiken, SC 29808, USA
}

\section{A R T I C L E I N F O}

\section{Article history:}

Received 15 February 2008

Received in revised form 9 June 2008

Accepted 11 June 2008

Available online 31 July 2008

\section{Keywords:}

Hydrogen absorbing materials

Phase transitions

Crystal structure

Strain, High pressure

X-ray diffraction

\begin{abstract}
A B S T R A C T
Ball-milled $\mathrm{NaAlH}_{4}$ was studied up to $15 \mathrm{GPa}$ in a diamond anvil cell (DAC) by X-ray diffraction using a synchrotron radiation source. Lattice parameters were determined from the X-ray diffraction data at various pressures up to $6.5 \mathrm{GPa}$. Intensity of the powder diffraction patterns decreased with increasing pressure. Amorphisation started at a pressure of $\sim 6.5 \mathrm{GPa}$ and completed at $13.5 \mathrm{GPa}$. Reversible phase transformation from amorphous phase to the tetragonal phase was observed. A fit to the pressure-volume data equation of state was obtained using the Birch-Murnaghan equation of state and the bulk modulus was found to be $52.16 \pm 0.9 \mathrm{GPa}$ which is twice higher than the unmilled $\mathrm{NaAlH}_{4}$.
\end{abstract}

(C) 2008 Elsevier B.V. All rights reserved.

\section{Introduction}

$\mathrm{NaAlH}_{4}$ has been proposed as a viable hydrogen storage media capable of supplying hydrogen at moderate temperatures and at rates required for fuel cell applications. These favorable characteristics, particularly the reversibility of $\mathrm{NaAlH}_{4}$ as a hydrogen storage media, were reported first by Bogdanovich et al. [1] and was immediately followed by extensive study of related complex metal hydrides by a number of researchers [2-6]. Reversibility and enhanced desorption kinetics were clearly demonstrated for $\mathrm{NaAlH}_{4}$ when doped with titanium and other transition metals [1-5]. Phase transitions and crystal structure modifications have been studied during the thermal decomposition of $\mathrm{NaAlH}_{4}$ [7,8]. Enhanced desorption kinetics were clearly demonstrated for $\mathrm{NaAlH}_{4}$ doped with $\mathrm{Ti}$ and/or Zr catalyst [9-11]. Ab initio calculations by projected augmented plane wave method indicate that $\mathrm{NaAlH}_{4}$ undergoes a phase transformation from tetragonal structure with space group $I 4_{1} / a$, i.e., $\mathrm{SrMgH}_{4}$-type structure to the $\beta$-orthorhombic $\left(\mathrm{Cmc}_{1}\right)$ structure at $6.43 \mathrm{GPa}$ with a $45 \%$ volume contraction [12]. It was also suggested that the $\beta-\mathrm{NaAlH}_{4}$

\footnotetext{
* Corresponding author at: Center for Study of Matter at Extreme Conditions, 11200 SW 8 th Street, Building VH, Room 140, Florida International University, Miami, FL 33199, USA. Tel.: +1 510486 7035; fax: +1 5104867588.

E-mail addresses: selva.raju@fiu.edu, rsvennila@yahoo.co.in (R. Selva Vennila).
}

stores more hydrogen volumetrically than the $\alpha$-phase and would, if stabilized at ambient conditions, be an interesting candidate for further studies with regard to hydrogen absorption/desorption efficiency. Recently Talyzin and co-worker [13] performed high pressure Raman measurements up to $17 \mathrm{GPa}$ on $\mathrm{NaAlH}_{4}$. They reported two possible phase transformations: one at $\sim 3 \mathrm{GPa}$ which was less obvious as a structural transformation, and a second at $\sim 12$ GPa to the orthorhombic structure. Our previous X-ray measurements on commercially available $\mathrm{NaAlH}_{4}$ showed the phase transformation to $\beta-\mathrm{NaAlH}_{4}$ phase with orthorhombic structure which is in agreement with the predicted structure by Vajeeston et al. [12] followed by amorphisation at $~ 13.6 \mathrm{GPa}$ [14].

In comparison, the related hydride $\mathrm{LiAlH}_{4}$ has a monoclinic structure at ambient conditions with space group $P 2_{1} / c$ and undergoes a slow phase transition from an $\alpha$-cubic to a $\beta$-phase. This transformation has been reported to occur between 2.2 and $3.5 \mathrm{GPa}$ [15]. Alternatively, $\mathrm{NaBH}_{4}$ under pressure shows a phase transformation from $\alpha$-cubic to $\beta$-tetragonal structure starting at $5.4 \mathrm{GPa}$ with an orthorhombic phase stabilized at pressures above $8.9 \mathrm{GPa}$ [16]. An electronic structure study by ab initio calculation indicated that the primary change corresponds to a narrowing of the band gap in $\alpha-\mathrm{NaBH}_{4}$, caused by broadening of sodium antibonding states in the conduction band [17]. In case of ammonia borane complex $\left(\mathrm{NH}_{3} \mathrm{BH}_{3}\right)$, two pressure-induced structural transitions were observed in this solid, in contrast to the temperature behavior where a single transition occurs. Raman spectra of $\mathrm{NH}_{3} \mathrm{BH}_{3}$ was 
studied up to $4 \mathrm{GPa}$ and it was found that the vibrational modes involving the $\mathrm{NH}_{3}$ group show negative pressure dependences, but the vibrations of the $\mathrm{BH}_{3}$ group have a positive dependence supporting the existence of the dihydrogen bond [18].

It has been shown that ball milling improves the hydrogen storage properties of hydrides including $\mathrm{NaAlH}_{4}[2-5,19,20]$. The enhanced hydrogen sorption properties of hydrides, in general, after ball milling has been attributed to: (i) the formation of a large amount of oxide-free surface, (ii) the reduction in grain size, and (iii) the introduction of lattice defects [21]. Milling essentially results in increasing the surface to bulk ratio, increasing grain and fault boundary densities that assist diffusion and the rate of $\mathrm{H}_{2}$ sorption. Therefore, it would be of great interest to study mechanochemically milled $\mathrm{NaAlH}_{4}$ to understand the effect of milling on the structural behaviour using high-pressure methods. In this paper, micro X-ray diffraction measurements were carried out using a synchrotron source under pressure up to $15 \mathrm{GPa}$.

\section{Experimental}

$\mathrm{NaAlH}_{4}$ (99\% purity from Sigma-Aldrich) was ball-milled for 60 min in a Spex 8000 ball mill vial with $6.35 \mathrm{~mm}$ and $12.7 \mathrm{~mm}$ stainless steel balls at room temperature under a dry argon atmosphere. Milling typically resulted in a reduction of particle size without decomposition. The crystal structure and purity of the milled alanate were checked by X-ray powder diffraction using $\mathrm{Cu} K \alpha$ radiation.

The high-pressure X-ray powder diffraction experiments were performed at beamline 16-IDB, HPCAT (High Pressure Collaborative Access Team) of APS (Advanced Photon Source) at Argonne National Laboratory. The monochromatic beam of wavelength $0.45657 \AA$ was focused to approximately $100 \mu \mathrm{m}^{2}$ and the data was recorded by a Mar345 image plate. The sample was loaded with mineral oil in a Mao-Bell diamond anvil cell (DAC). A stainless steel gasket of thickness $50 \mu \mathrm{m}$ and hole size $200 \mu \mathrm{m}$ served as the sample chamber with a few grains of platinum metal loaded with the sample as a pressure marker. X-ray diffraction (XRD) analysis of the ball-milled sample shows single phase $\mathrm{NaAlH}_{4}$ having tetragonal structure with space group $I 4_{1} / a$ identical to the unmilled sample. Lattice parameters were determined from Rietveld structure refinement using GSAS with GUI interface [22-24].

In order to determine particle size, lanthanum hexaboride $\left(\mathrm{LaB}_{6}\right)$ crystals of particle size $2 \mu \mathrm{m}$ were used as the standard. XRD pattern of $\mathrm{NaAlH}_{4}$ (both as-received and ball-milled) and $\mathrm{LaB}_{6}$ were recorded at the same conditions. Rietveld structure refinement was performed on the angle dispersive X-ray diffraction (ADXRD) pattern of the above-mentioned materials, using GSAS software. Refined value of Lorentzian-Scherrer broadening term in GSAS profile function of $\mathrm{LaB}_{6}$ was used as an instrumental broadening. This value was subtracted from the corresponding broadening term of the $\mathrm{NaAlH}_{4}$ samples to determine diffraction line broadening related to the particle size effect.

\section{Results and discussion}

Lattice parameters of unmilled and milled samples are given in Table 1. Gomes et al. [20] reported decreasing of the unit cell volume and $c / a$ ratio after ball milling which is in agreement with our results. These observations can be attributed to the increase of surface to volume ratio in the particles. [24]:

Particle size was determined by substituting ' $X$ ' in the relation

$P(\AA)=\frac{18,000 B \lambda}{\pi X}$,

where $B$ is the Scherrer constant (0.9), $\lambda$ is the $\mathrm{X}$-ray radiation wavelength, and $X$ is the Lorentzian-Scherrer broadening term in GSAS profile function. From the above equation, particle size of as-received and ball-milled $\mathrm{NaAlH}_{4}$ samples were found to be

Table 1

Comparision of lattice parameters of the milled and unmilled $\mathrm{NaAlH}_{4}$

\begin{tabular}{lllll}
\hline $\mathrm{NaAlH}_{4}$ & $a(\AA)$ & $c(\AA)$ & $c / a$ & $V\left(\AA^{3}\right)$ \\
\hline Unmilled & $5.0428(3)$ & $11.400(1)$ & 2.2606 & $289.91(2)$ \\
Milled & $5.0253(3)$ & $11.354(1)$ & 2.2593 & $286.74(3)$ \\
\hline
\end{tabular}

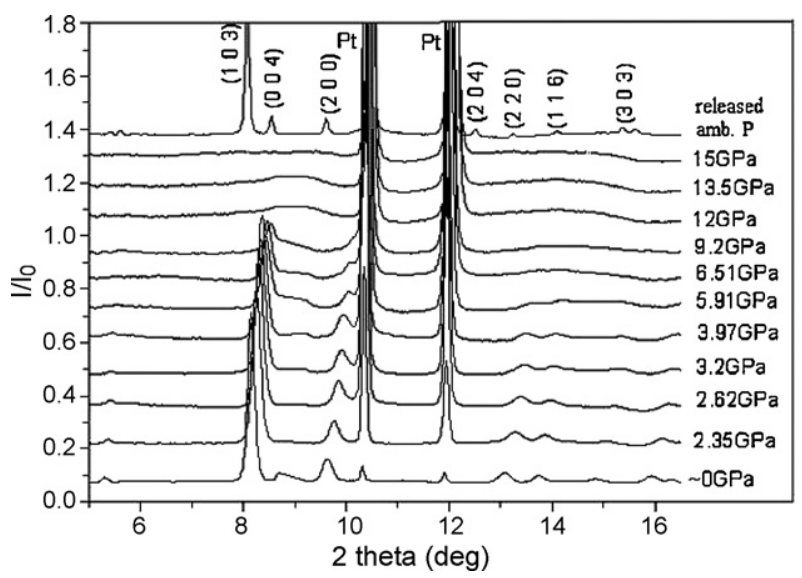

Fig. 1. Comparision of the ADXRD data collected for ball-milled $\mathrm{NaAlH}_{4}$ for various pressures at room temperature. Note the dissapearance of the peaks at $13.5 \mathrm{GPa}$.

$1.08 \mu \mathrm{m}$ and $715 \mathrm{~nm}$, respectively. It was found that ball milling of the $\mathrm{NaAlH}_{4}$ decreases the particle size by $\sim 30 \%$. Fig. 1 shows the ADXRD pattern of $\mathrm{NaAlH}_{4}$ collected at various pressures up to 13.5 GPa. Amorphisation of the sample was observed between 12 and $13.5 \mathrm{GPa}$.

The variation of lattice parameters with pressure up to $6.8 \mathrm{GPa}$ is shown in Fig. 2. It is observed that $a$ and $c$ lattice parameters decrease with increasing pressure with a $c / a$ ratio of $\sim 2.2$ maintained. It was observed that the amorphisation of the ball-milled sample occurred at approximately $1.5 \mathrm{GPa}$ above that of unmilled $\mathrm{NaAlH}_{4}$. Above $6.8 \mathrm{GPa}$ the structural fit could not be obtained due to the broadening and disappearance of all Bragg reflections other than $(013)$ and $(112)$ peaks. This is an indication of the onset of amorphisation of milled $\mathrm{NaAlH}_{4}$

The experimental data were fitted with a third order Birch-Murnaghan equation of state (EOS) [25]:

$$
\begin{aligned}
P= & \frac{3}{2} K_{300,0}\left[\left(\frac{V_{300,0}}{V}\right)^{7 / 3}-\left(\frac{V_{300,0}}{V}\right)^{5 / 3}\right] \\
& \times\left[1-\frac{3}{4}\left(4-K_{300,0}^{\prime}\right)\left(\frac{V_{300,0}}{V}\right)^{2 / 3}-1\right]
\end{aligned}
$$

where $K_{300,0}, K_{300,0}^{\prime}$, and $V_{300,0}$ are the bulk modulus, its pressure derivative and volume of unit cell at zero pressure and

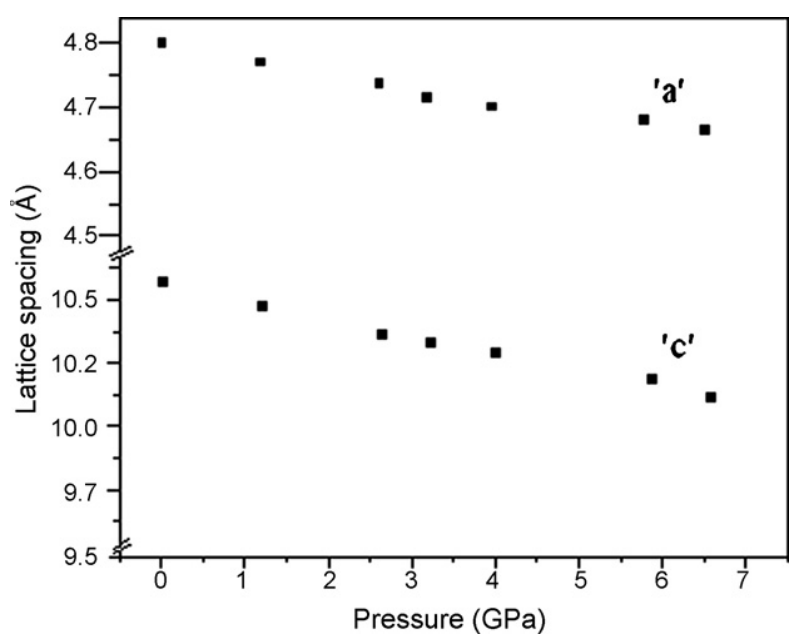

Fig. 2. Lattice parameters variation with pressure for the ball-milled $\mathrm{NaAlH}_{4}$ up to $6.8 \mathrm{GPa}$. 


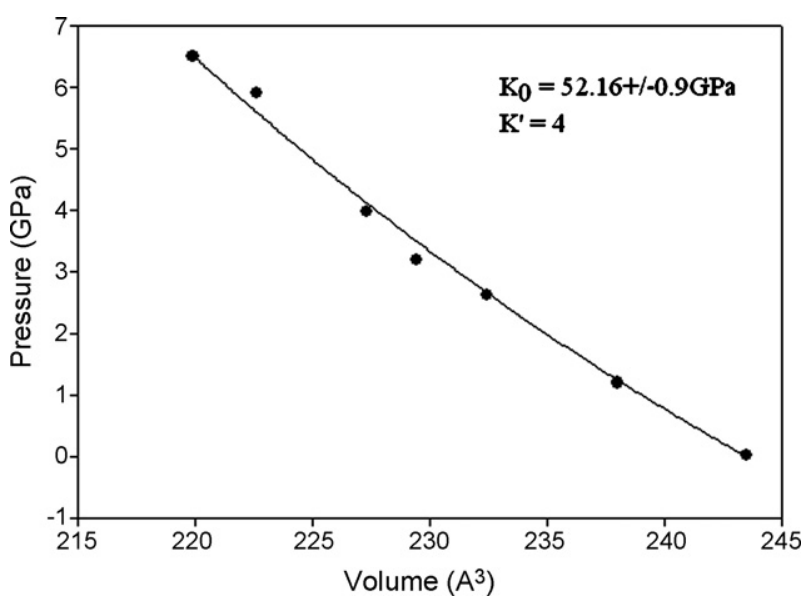

Fig. 3. Birch-Murnaghan equation of state fit obtained for ball-milled $\mathrm{NaAlH}_{4}$ with $\mathrm{K}^{\prime}$ set to 4.

$300 \mathrm{~K}$, respectively. Experimental $P-V$ data were fitted using the Marquardt-Levenberg least square fitting procedure with a commercial sigma plot (SPSS) program. Fig. 3 shows the behavior of relative volume with pressure, where the EOS fit was obtained using the Birch-Murnaghan equation of state with $K^{\prime}$ constrained to 4 . The bulk modulus of ball-milled $\mathrm{NaAlH}_{4}$ increased from $25.3 \pm 1.3 \mathrm{GPa}$ [14] to $52.16 \pm 0.9 \mathrm{GPa}$, which is a surprisingly large positive effect.

\section{Conclusion}

Lattice parameters were determined by Rietveld refinement and found to be: $a=4.827(2) \AA ; \quad c=10.650(3) \AA ; \quad c / a=2.206(3)$; $V=248.2(2) \AA^{3}$. The intensity of the powder diffraction pattern decreased with increasing pressure. Amorphisation of the sample started at a pressure of $\sim 6.5 \mathrm{GPa}$ and was completed at $13.5 \mathrm{GPa}$. The structure was found to be reversible when the pressure was released. The new phase observed before amorphisation in the case of the unmilled sample (i.e., $\beta-\mathrm{NaAlH}_{4}$ ) $[26,14]$ was absent in the ball-milled sample. A recent report on the X-ray diffraction study of $\mathrm{NaAlH}_{4}$ indicates a phase transformation to the monoclinic $\beta$-phase which corresponds to the amorphisation pressure in our observation. This pressure-induced amorphisation must have been influenced by the presence of mineral oil, which can be explained by the variation of the hydrostatic conditions [27]. We report the absence of high-pressure phases in the ball-milled samples concluded from both the X-ray and Raman experiments. This could be due to the surface state domination of the phase transformation. The increase in the surface area (with strong stress effects) to bulk volume ratio, resulting from ball milling could have forced the system to an amorphous phase, as an easier path during the phase transformation $[28,29]$. The experiment was repeated two times to check the amorphisation pressure and presence of the high-pressure phase. It was concluded that the ball milling caused changes in the phase transformation pressure by $1.5 \mathrm{GPa}$ and decreased the compressibility by almost a factor of 2 . This is caused by the size-induced pressure effect due to larger surface area in the nanophase materials when compared to their bulk. [30,31].

To study the size effect with pressure, milled $\mathrm{NaAlH}_{4}$ was loaded with mineral oil and the XRD pattern was recorded up to $11.45 \mathrm{GPa}$.
The pressure was then released to $2 \mathrm{GPa}$ and once again increased to $13.5 \mathrm{GPa}$ in order to observe any changes in the size effect. No high-pressure phase was observed prior to amorphisation contrary to the unmilled $\mathrm{NaAlH}_{4}$. Hence, we conclude that pressurising the sample to $11 \mathrm{GPa}$ did not have any effect on the particle size.

\section{Acknowledgements}

We acknowledge the Air Force Grant No. 212600548 and National Science Foundation grant no. 212600556 for the financial support to carryout the above research work. This work was performed at HPCAT (Sector 16), Advanced Photon Source (APS), Argonne National Laboratory. Use of the HPCAT facility was supported by DOE-BES, DOE-NNSA (CDAC), NSF, DOD-TACOM, and the W.M. Keck Foundation. Use of the APS was supported by DOE-BES, under Contract No. W-31-109-ENG-38. Drs. Zidan, Anton, Stowe Berseth would like to thank the DOE Office of Basic Energy Science for support under grant no. KP1301020.

\section{References}

[1] B. Bogdanovich, R. Brand, A. Marjanovich, M. Schickardi, M.J. Tolle, J. Alloys Compd. 302 (2000) 36-58.

[2] C.M. Jensen, R.A. Zidan, N. Mariels, A.G. Hee, C. Hagen, Int. J. Hydrogen Energy 24 (1999) 461.

[3] R.A. Zidan, S. Takara, A.G. Hee, C.M. Jensen, J. Alloys Compd. 285 (1999) 119.

[4] A. Zaluska, L. Zaluska, J.O. Strom-Olsen, J. Alloys Compd. 298 (2000) 125-134.

[5] D.L. Anton, J. Alloys Compd. 356-357 (2003) 400-404.

[6] S. Satyapal, J. Petrovich, C. Read, G. Thomas, G. Ordaz, Catal. Today 120 (2007) 246-256, therein.

[7] R.K. Ahluwalia, Int. J. Hydrogen Energy 32 (2007) 1251.

[8] E.C. Ashby, P. Kobetz, Inorg. Chem. 5 (1966) 1615.

[9] M.P. Balogh, G.G. Tibbetts, F.E. Pinkerton, G.P. Meisner, C.H. Olk, J. Alloys Compd. 350 (2003) 136-144.

[10] K.J. Gross, S. Guthrie, S. Takara, G. Thomas, J. Alloys Compd. 297 (2000) 270-281.

[11] K.J. Gross, G.J. Thomas, C.M. Jensen, J. Alloys Compd. 330-332 (2002) 683-690.

[12] P. Vajeeston, P. Ravindran, R. Vidya, H. Fjellva, A. Kjekshus, Appl. Phys. Lett. 82 (14) (2003).

[13] A.V. Talyzin, B. Sundqvist, High Pressure Res. 26 (September (3)) (2006) 165-173.

[14] R. Selva Vennila, L. George, V. Drozd, S.K. Saxena, Materials Letters (2008) to submit.

[15] R.S. Chellappa, D. Chandra, S.A. Gramsch, R.J. Hemley, J. Lin, Y. Song, J. Phys. Chem. B 110 (2006) 11088-11097.

[16] R.S. Kumar, A.L. Cornelius, Appl. Phys. Lett. 87 (2005) 261916.

[17] C. Moysés Araújo, R. Ahuja, A.V. Talyzin, B. Sundqvist, Phys. Rev. B 72 (2005) 054125.

[18] S. Trudel, D.F.R. Gilson, Inorg. Chem. 42 (2003) 2814-2816.

[19] G.P. Meisner, G.G. Tibbetts, F.E. Pinkerton, C.H. Olk, M.P. Balogh, J. Alloys Compd. 337 (2002) 254-263.

[20] S. Gomes, G. Renaudin, H. Hagemann, K. Yvon, M.P. Sulic, C.M. Jensen, J. Alloys Compd. 390 (2005) 305-313.

[21] R.A. Dunlap, Z.H. Cheng, G.R. MacKay, J.W. O’Brien, D.A. Small, Hyperfine Interact. 130 (2000) 109-126.

[22] A.C. Larson, R.B. Von Dreele, General Structure Analysis System (GSAS), Los Alamos National Laboratory Report LAUR 86-748, 2000.

[23] B.H. Toby, J. Appl. Crystallogr. 34 (2001) 210-221.

[24] A.C. Larson, R.B. Von Dreele, GSAS Manual, Los Alamos National Laboratory, 1985, ftp://ftp.lanl.gov/public/gsas.

[25] N. Funamori, T. Yagi, T. Uchida, Geophys. Res. Lett. 23 (1996) 953.

[26] R.S. Kumar, E. Kim, O. Tschauner, A.L. Cornelius, Phys. Rev. B 75 (2007) 174110.

[27] L.C. Ming, S.R. Shieh, A. Jayaraman, S.K. Sharma, Y.H. Kim, J. Phys. Chem. Solids 60 (1999) 69-81.

[28] S. Klotz, G. Hamel, J.S. Loveday, R.J. Nelmes, M. Guthrie, A.K. Soper, Phys. Rev. Lett. 28 (89) (2002) 285502-285506.

[29] Pon, J.M. Leger, J. Haines, L.S. De Oliveira, C. Chateu, A. Le Sauze, R. Marchand, S. Hull, J. Phys. Chem. Solids 2 (60) (1999) 145-152.

[30] R. Selva Vennila, S.R. Kulkarni, S.K. Saxena, H.P. Liermann, S. Sinogeikin, Appl. Phys. Lett. 89 (2006) 261901-261903.

[31] Z. Wang, Y. Zhao, D. Schiferl, C.S. Zha, R.T. Downs, T. Sekine, Appl. Phys. Lett. 83 (2003) 3174-3176. 